RAISING THE TAKE-UP OF SOCIAL ASSISTANCE BENEFITS THROUGH A SIMPLE MAILING: EVIDENCE FROM A FRENCH FIELD EXPERIMENT

SYLVAIN CHAREYRON, DAVID GRAY, YANNICK L'HORTY 
ISSN 2110-5472 


\title{
Raising the take-up of social assistance benefits through a simple mailing: evidence from a French field experiment
}

\author{
Sylvain ChAREYRON *, David GRAY ${ }^{\dagger}$ and Yannick L'HorTY
}

March 2017

\begin{abstract}
This paper is related to the puzzle of an observed unduly low take-up rate for social assistance benefits in France. In order to investigate this phenomenon, we conduct an experimental evaluation in the form of a Randomized Control Trial involving the influences of informational complexity and availability. We examine the impact of a change in the information set which is sent to these households just after they claim the benefit, seeking a behavioral response to this particular 'nudge'. Our findings suggest that costless actions on the part of program administrators are able to substantially increase take-up for certain types of beneficiaries. In order to be effective, these actions should target households according to their individual attributes.
\end{abstract}

Keywords: non-take-up of social insurance benefits, RCT, informational nudge

Codes JEL: D03, H24, M38

\footnotetext{
* Sylvain Chareyron, Université Paris-Est, ERUDITE (EA 437), TEPP-CNRS (FR 3435), UPEC, UPEM, F-77454 Marne-La-Vallée, France, sylvain.chareyron@univ-paris-est.fr $\uparrow$ David GRAY, University of Ottawa, David.Gray@uottawa.ca

- Yannick L'HorTy, Université Paris-Est, ERUDITE (EA 437), TEPP-CNRS (FR 3435), UPEC, UPEM, F-77454 Marne-La-Vallée, France, yannick.lhorty@u-pem.fr
} 


\section{Introduction}

In 2009 the regime of means-tested, social assistance benefits in France underwent a profound transformation with the introduction of a new benefit called the Revenu de Solidarité Active (RSA - the Solidarity Earned Income Supplement), which replaced its longstanding predecessor known as the Revenu Minimum d'Insertion (RMI - Minimum Integration Income). With an eye towards strengthening work incentives and avoiding the well-known and socially and economically harmful 'welfare trap', the new income-support benefit was designed to sharpen the incentives for recipients to earn labour market income. More specifically, on the margin increases in labour market income earned would no longer be clawed back by an offsetting reduction in social assistance transfers. The aim was to guarantee that starting or returning to work, as well as increasing the number of hours worked, would unambiguously increase the total income received by poor households. An unexpected and disconcerting effect of this reform, however, has been an apparent decrease in the overall take-up rate among poor households. Indeed, a study conducted by the evaluation council of the RSA that assessed the incidence of take-up of the new benefit concluded that $68 \%$ of the newly eligible beneficiaries did not take-up their benefits (Domingo and Pucci, 2011). The extent of this phenomenon of what was viewed as unduly low take-up resulted in the development of another new reform labelled the "prime d'activité" (activity bonus) that was implemented in 2016.

The non-take-up of social benefits, which is a major concern for other countries as well as France, implies that social policy measures targeted at vulnerable social groups often fail to reach these intended beneficiaries, which undermines their objectives of alleviating poverty (i.e. the passive function) and ultimately facilitating integration or re-integration into the labour force (i.e. the active function). In addition to these policy challenges, it poses an economic puzzle. The fact that a significant number of potential beneficiaries fail to take-up benefits or to maintain their eligibility - especially in the form of income transfers - runs directly counter to rational choice making according to standard neo-classical microeconomic theory. This phenomenon remains a puzzle both from a public policy perspective as well as from an economic behavioural point-of-view.

Several competing economic explanations as to why eligible beneficiaries fail to takeup income benefits (or to maintain eligibility for them) have been proposed in the economics literature. In our paper we evoke three channels in no particular order. First, they might not 
know that they are eligible because the relevant information is simply unavailable to them, as suggested in the application of Daponte, Sanders, and Taylor (1999). This effect involves little more than the non-transmission of information. The second possible channel is that they are aware of their eligibility, but upon weighing the perceived costs against the perceived advantages, they decline to participate. Those costs might involve the social stigma associated with enrollment, as suggested by Currie (2006) and Moffitt (1983), or they might consist of transactions costs, as suggested by O'Donoghue and Rabin (1999). The third channel invokes the behavioural economics approach. To the extent that this choice is not rational from a purely neo-classical decision-making perspective, this approach, with its emphasis on psychological, sociological, and neuro-scientific barriers, might be applicable. Potential claimants might know that they are eligible, and they might be tempted by the benefits, but they fail to take-up the benefits for reasons such as procrastination or psychological aversion to program complexity. The former factor is central to applications involving savings behavior authored by Jones (2010) and Madrian and Shea (2001). The latter factor is central to an application involving social assistance by Bertrand, Mullainathan, and Shafir (2006). The relative applicability of these three distinct channels is an interesting question for applied economic research, but they are particularly important for public policy analysis because they involve sharply different policy repercussions.

The primary objective of this paper is to conduct an empirical investigation of the phenomenon of non-take-up couched, for the most part, within the framework of behavioural economics. Our methodological approach is experimental evaluation in the form of a randomized controlled trial (RCT). This technique is increasingly utilized in the realm of behavioural economics to analyse the prevalence of human tendencies that appear to be inconsistent with the predictions of the basic neoclassical, utility-maximization model. To mention just a few well-known applications, the RCT methodology has been used to study information and social network effects on retirement planning decisions (Duflo and Saez 2003), vaccination against diseases (Milkman et al., 2011), tax compliance (Hallsworth et al., 2014), school choice and the associated academic achievement outcomes (Hastings and Weinstein 2008), and older workers' choices regarding labour market participation as they relate to the provision of information regarding Social Security provisions (Liebman and Luttmer, 2015). In such applications, the intervention of the experiment often consists of conveying minor changes in the presentation of information and observing subsequent responses. 
Our outcome variable for the RCT is not the initial choice among the eligible population to apply for RSA benefits, but rather the choice to abide by the program`s regulations in order to maintain eligibility. Specifically, shortly after taking up RSA benefits, recipients are required to meet with a case-worker under the threat of losing their entitlement to benefits. A non-negligible number of recipients place the benefit entitlement in jeopardy by failing to comply with this requirement. As such our results pertain not to the initial take-up rate, but rather to the continuation rate conditional on initial receipt.

It is thought that one important explanatory variable driving the phenomenon of nontake-up (or non-continuation in our case) is the quantity and the nature of the information that potential beneficiaries have. Following the technique adopted by Bhargava and Manoli (2015), we employ a protocol that changes in exogenous fashion the information provided to beneficiaries. Employing the technical term attributed to Sunstein (2014) and Thaler (2015), we apply two distinct "low-touch" nudges to two separate treatment groups. As explained in the survey paper by French and Oreopoulos (2016), 'low touch' nudges involve small tweaks to the modes of communication, which are generally cheap to implement and focus on making decisions more salient and simpler for the individual to notice and comprehend. ${ }^{1}$ We are able to test for the applicability of the latter two of the three behavioural channels that are mentioned above. With respect to the second one, one of our protocols provides additional information that is germane to the valuation of both monetary and non-monetary aspects associated with participation that might counteract the effects of stigma and change the tradeoff between costs and benefits of the decision to participate in the interview. With respect to the third channel, our protocol involves only a simplification of the information provided to the beneficiaries, which has been found to generate important effects in other well-known experiments, such as those conducted by Bettinger et al. (2012), Chetty and Saez (2013), and Saez (2009).

The RCT was carried out in the French department of Seine-et-Marne (Seine and Marne), which is located within the metropolitan Paris area southeast of Paris proper and

\footnotetext{
${ }^{1}$ In contrast "high-touch" nudges involve significant changes to the individual's environment and often include personal interaction.
} 
accounts for about $11 \%$ of the population of the metropolitan Paris area. This geographical and administrative unit can be thought of as a county. Seine-et-Marne consists of a mix of urban and rural areas and is relatively large in terms of population (1.4 million inhabitants) and geographical area. In France, it is the departmental unit that administers the income support programs on behalf of the Federal government. Given this institutional framework, we are able to obtain and exploit data that are specific to this department yet are nationally uniform in terms of reporting practices, organizational structure, and content. Given the characteristics of the data set and the fact that Seine-et-Marne is a representative department, our results should be applicable to much of France.

The intervention itself consists of two fairly minor modifications of the content of the official letter which is sent to beneficiaries that convokes them to confer with a case-worker. The measured outcome is the event of participating in these counseling services. We find that this relatively mild intervention increased that participation rate by 12 percentage points relative to a control group. This impact was limited to young male subjects, however. Our preferred interpretation of the results is that participation is influenced by the content of the information provided by the mailing as it relates to the individualized needs of the claimant. In our context, if young men have a greater capacity and availability for job search, due perhaps to facing lighter family responsibilities, they might be more interested in obtaining information pertaining to active labour market policy measures provided by the case worker than what would otherwise be the case. The policy repercussion is that interventions like this can prevent certain beneficiaries from being disentitled to income benefits, which in turn would raise the continuation rate (or lower the disqualification rate) for the receipt of social assistance benefits.

The first section of the paper provides some background on the institutional apparatus for the French social assistance income support regime and the associated phenomenon of non-take-up. The second section presents the experimental design and the empirical framework. The final section presents the results and offers interpretations. 


\section{Background information on income support regime}

\section{a. Program structure and summary}

During the year of 2014, the French social assistance program disbursed more than $€ 10$ billion in benefits to nearly 2.5 million people. ${ }^{2}$ It is administered at the county level, but the criteria for eligibility, the provisions, the appertaining regulations, and the financing are determined nationally. Entitlement is assessed at the family unit, defined as either a single individual or a couple, and includes all dependent children under the age of 25 . The definition of the household is the legal familial situation. To claim these benefits, individuals have to declare their financial resources and provide information upon which entitlement is calculated. This form has to be completed, updated, and filed every three months.

This regime consists of two components: basic income support and additional income support. The basic income benefit is paid when the household receives no income stemming from employment. The amount provided is a demogrant that varies according to the composition of the family. In the case of a childless, single individual with no earned income, the basic monthly benefit is $€ 499.31$, while it is increased to $€ 748.97$ for a single individual with one child. ${ }^{3}$ If a family unit benefits from a housing allowance, owns its home, or receives free housing, a flat-rate amount is deducted from the benefit. The second component (Additional income support) is paid to people earning some income from employment but who still have sufficiently low income in order to be eligible. This component permits the household to keep $€ 0.62$ for each additional euro of income earned from employment, implying a clawback rate of $38 \%$.

The overall income support benefit is paid only to individuals whose monthly entitlement is assessed at more than 6 euros. An age criterion for eligibility also applies; an individual must be older than 25, with the exception of single parents who are under 25 . Finally, there are also special eligibility rules for people who are not French citizens. For instance Europeans citizens must have lived in France for at least three years prior to the date of their claim.

\footnotetext{
${ }^{2}$ This was the stock of beneficiaries at the end of 2014.

${ }^{3}$ The amounts are provided for 2014.
} 


\section{b. The steps required for new entrants to the RSA}

The receipt of the benefit is contingent on a number of requirements. In order to facilitate integration into the labour market (i.e. a return to work), the beneficiaries are monitored. For this purpose each new entrant in the program is assigned a case-worker who is charged with following him/her for the duration of their claim. The beneficiaries receive a mailing from the departmental agency that administers the RSA regime a few times after entering the program and commencing with receipt of benefits. This initial letter instructs them to establish contact with their particular case-worker within seven days, after which a subsequent mailing is sent to those who have not yet contacted their case worker. ${ }^{4}$ After that initial contact, he/she has to make an appointment for an interview in order to assess their social situation and vocational/professional profile. More specifically, social needs such as the provision of child care and transportation, as well as the skill set and educational attainments, are assessed. The result of the interview will determine the type of assistance and counselling with which the beneficiary will be provided in order to be successfully integrated - or reintegrated - into the labour market. The next step is for the beneficiary to sign his/her commitment contract with the administration. It stipulates the reciprocal commitments made by both parties regarding the reintegration, which reflect the profile of the beneficiary. It is valid for six months and must be renewed at the end of that period.

An important point for our analysis is that these administrative steps are required in order to continue receiving the benefit. The beneficiary can be removed from the program, and hence disentitled to benefits, if he/she fails to carry out these steps and/or fails to respect the terms of the commitment contract. In the year 2012, of the inflow of 8,766 new entrants to the RSA regime in the department of Seine-et-Marne who received the mailing, 35\% (3,068 individuals) failed to participate in the guidance interview. That specific event is the outcome of interest for our study, but we employ more recent data. In that same year (2012), the department of Seine-et-Marne deliberated on 4,147 cases of possible suspension of benefits some of which dated back to 2011. $36.5 \%$ of those cases (1,514 individuals) have effectively been suspended from receiving benefits, the primary reason for which was failure to show up for the guidance interview. Nearly $42 \%$ (636 individuals) of the cases of effective suspension

\footnotetext{
${ }^{4}$ Since a reminder notice is sent to them on the seventh day, technically the time limit of seven days to contact the case worker is not strictly observed. Suspension does not occur for households that slightly exceed this limit.
} 
are due to that justification, which translates into a rate of suspension of about $20 \%(636$ individuals of the 3,068 individuals who did not participate in the guidance interview), despite the enhancement of the administrative controls. ${ }^{5}$ To summarize these figures, the nonparticipation rate for the interview was $35 \%$, the overall incidence of effective suspension was $37 \%, 42 \%$ of these suspensions were for that reason, and the suspension rate for those who did not participate was $20 \%$.

The other reasons for disentitlement are: commitment contract not signed, commitment contract subsequently not honored, commitment contract not renewed, and/or removal from the rolls of the national employment agency (called "le Pole Emploi"). ${ }^{6}$ The corresponding figures for the preceding year of 2011 were of the same order of magnitude, despite the fact that the flow of new entrants was greater. In that year $57 \%$ of the cases of effective suspension were due to the failure to partake in the guidance interview.

\section{c. Non-take-up of social assistance benefits}

Although the phenomenon of non-take-up at the initial stage of the application process was our initial research motivation, we do not deal with it directly for several reasons. First and foremost, as is the case for many social insurance programs, accurately measuring and modeling the take-up rate, which is typically calculated as the ratio of the number of actual beneficiaries to eligible individuals/households, is empirically challenging. The difficulty stems from the fact that while the quantity in the numerator is drawn from very reliable administrative data, the corresponding quantity in the denominator is not usually available from that source. A common strategy to deal with this difficulty is to conduct surveys that hopefully are representative of the targeted, eligible population. One procedure is to link the two data sets - each containing the relevant data series - together in order to estimate that ratio and conduct further empirical analysis. ${ }^{7}$ Another procedure is to retain the sampling structure of the broad survey, but to import the relevant administrative data into the survey. A third

\footnotetext{
${ }^{5}$ Note that this estimate may not be exact as some case of suspension may concern the beneficiaries of 2011.

${ }^{6}$ There is some overlap in the beneficiaries of the RSA and those of the "Pole Emploi". Registration with the latter is required in order to access unemployment insurance benefits, and they also provide the active labour market policy programs. Members of the overlapping group likely had prior work experience.

${ }^{7}$ In the ideal construction, the set of subjects represented in the numerator is a strict subset of the set of subjects in the denominator, and all subjects in the denominator must meet the eligibility criteria.
} 
alternative procedure that is sometimes feasible is to collect all of the relevant information directly in the survey.

With respect to the former social assistance regime (the RMI), published estimates of the overall rate of non-take-up vary considerably. Terracol's (2002) analysis suggested a rate of $35 \%$, while Domingo and Pucci (2012) estimated a $50 \%$ non-take-up rate for the RSA regime in 2010. These calculated rates mask great disparities between those estimated for the basic income support component, for which the rate was estimated to lie between $29 \%$ and 35 $\%$ (Chareyron 2014), and those estimated for the supplemental income support component, for which the rate was estimated to be much higher at $68 \%$. In a similar vein, another study by Chareyron and Domingues (2016) estimated that in 2012, $18 \%$ of the eligible homeless population was not receiving benefits. ${ }^{8}$

We have argued above that measuring the overall non-take-up is problematic for statistical reasons. Furthermore, while modelling would yield information useful for understanding the underlying factors, it is not clear that it would be linked in direct fashion to public policy recommendations for reforms. We narrow the scope of our study by analyzing a facet of the overall take-up rate, namely the continuation rate. The outcome of interest is the incidence of non-compliance with the requirement to meet with a case-worker. As mentioned above, they risk being disentitled to income benefits. When this event occurs, they are removed from the stock of beneficiaries while still remaining in the stock of potential beneficiaries, thus lowering the stock-based measure of the take-up rate.

The research strategy that we adopt is quite suitable for analyzing that outcome. The RCT method is appropriate for the purposes of both analyzing the effect of feasible, practical, policy-related actions and investigating the underlying behavior. The advantages of our research design include the fact that we deal with a well-defined and easily observable outcome, and we achieve identification through randomization. As an RCT is generally conducted by an administrative operator of a social insurance program, all of the at-risk population is observed, although its application is conditioned on initially participating in it.

\section{Research Design}

\footnotetext{
${ }^{8}$ This particular population was not included in the previous estimates of non-take-up to the income support in France (Chareyron 2014; Domingo and Pucci 2011) and is generally not included in any estimates of non-takeup (Bargain, Immervoll, and Viitamäki 2012; Riphahn 2001; Tempelman and Houkes-Hommes 2015).
} 


\section{a. Experimental Sample}

As explained above, our analysis does not involve the initial take-up rate at the point when potential beneficiaries first file their claims, i.e. the take-up rate relative to the inflow. We focus on the outcome of participation in the required interview and the establishment of a contract with the agency - an event that is observed and reported with complete accuracy. The experiment consists of an intervention aiming to improve participation in the guidance interview. The sample consists of households from Seine-et-Marne who entered the income support program between October 2014 and March 2015 (except for beneficiaries depending initially on the employment agency, known as the "pole Emploi"). The sample is comprised of households eligible for the income support program. During the six months of the experiment, 4,032 households were followed, of which 2,332 were headed by males, and 1,700 were headed by females. The mean and the median ages were 35 years and 32 years, respectively. Age, sex and city of residence are the only household characteristics of which we have knowledge.

\section{b. Hypotheses}

We formulate four hypotheses to explain why some beneficiaries do not follow the regulations in order to ensure continued receipt of their benefits, the first two of which appeal to behavioural economics. The first proposition is that beneficiaries may have difficulties in understanding the message of the letter due to low reading skills or to a lack of attention. The second conjecture is that beneficiaries may have decided to claim the benefit without knowing that they would be obligated to follow a complex (at least in the eyes of some) process upon filing the initial claim. Upon learning of this obligation, they reassess the concomitant cost and fail to comply. The third possibility is the impending threat of suspension that beneficiaries face if they fail to participate might not be viewed as credible. Indeed, we mentioned rough evidence above that the average probability of being sanctioned is below 0.5 , but it is unknown what the perceived probability is in the minds of the recipients. The last possibility is that the elapsed time between the commencement of benefit receipt and the occurrence of the interview may be so long that the household that was initially eligible is no longer eligible (for some other unknown reason) by the time of the scheduled guidance interview. Due to the confines that are imposed on us by the sample size and the research design possibilities, we can address only the first two hypotheses. 


\section{c. Experimental protocol}

The experiment was launched in September 2014. Formal mailings were sent by the Conseil General de Seine-et-Marne (General Council of Seine and Marne) in the usual way: by sending formal requests through the postal service to the new beneficiaries at the end of each month. The experiment consisted of two variations in the content of the mailings. Subjects were either sent the standard letter or one of two alternative letters. Since all of these mailings sent by the General Council are official, formal letters, there are still particular constraints that apply to their content and format. The mailings consisted of a one-page, onesided enclosure (i.e. the notice itself) that was sent in an envelope. The notice informed the new beneficiary that he/she would be referred to a single case-worker and followed by that person for the duration of the period of benefit. The beneficiary was obligated to contact this case worker within seven days. The letter presented the steps which had to be completed, explained their purpose, and indicated the sanction that could be incurred in case of noncompliance.

The hypotheses that we investigate pertaining to the choice of whether or not to participate in the guidance interview involve the behavioural bias commonly labelled as "inattention" in the literature. Although all subjects were aware of the existence of the income support program, as they had successfully filed claims, households may have an erroneous view of the eligibility validation process as well as the steps that they have to follow in order to continue receiving benefits. To provide one example, they may not be aware that the absence of a signature on the commitment contract, which is discussed and drafted during the guidance interview, can lead to suspension of benefits. Upon becoming totally informed of their obligations, they might upwardly re-evaluate the costs that they face and decide not to participate in the guidance interview.

The control group receives the usual letter of initiation, while the two treatment groups receive an informational "nudge". The first treatment consists of receiving a letter that is written such that the information that it conveys is easy to understand, thus simplifying and clarifying the standard letter. While it contains only the most essential information, it still indicates the requirement that is mentioned above. This informational nudge is a case of "applied simplification", as labelled in Bhargava and Loewenstein's (2015) brief essay on the role of behavioural economics in public policy. One counterfactual scenario is that recipients experience a high (real or perceived) cost of reading the usual, standard form and/or of setting 
up the meeting, and actively choose to ignore the form. This could be due to a 'mental bandwidth deficit', described in Mullainathan and Eldar Shafir (2013), whereby certain individuals have a low cognitive 'bandwidth' to devote to thinking about choices involving tradeoffs. This trait is thought to be exacerbated by stressors associated with living in the state of poverty. The exact nature of the behavioural bias in this case is inattention. The causal effect would operate through reducing the real or perceived costs of reading the form.

The other counterfactual scenario is that the recipients follow routines/rules of thumb such that ignoring most forms that they receive is just their default behavior. This behavioural bias is not really associated with inattention but with a 'system-1-type' choice-making procedure, i.e. one made without deliberate thought. The causal effect would involve a behavior whereby ignoring (apparently) non-trivial letters is their default choice while ignoring really simple ones is not. Our research design and data availability do not allow us to discern between these two interpretations.

The second treatment consists of receiving a letter that is designed to highlight the potential benefits that are involved with participating in the guidance interview. This informational nudge is a case of "informational salience", again borrowing from Bhargava and Loewenstein (2015). By rendering the unexpected benefits more salient, it is designed to investigate whether this provision of supplemental information can play a role in inducing them to participate in the guidance interview. More specifically, the mailing highlights both features of the programs related to the receipt of the income benefit as well as the support measures that can facilitate the re-integration into the labour market. The programs and measures that accompany income support, such as the public transportation benefit in the Ilede-France (i.e. greater Paris) area (labelled the 'FGT'), are not always well-known. ${ }^{9}$ It mentions that the beneficiary has a right to receive this free public transportation benefit. It also explicitly mentions that the beneficiary will be followed by a single case-worker in order to develop an action plan involving counselling and/or personal or professional training tailored to the beneficiary's profile, thus ensuring continuity. The counterfactual scenario is that recipients face the tradeoff associated with participating in the guidance interview with a 'bandwidth' deficit such that they do not contemplate the potential benefits. The causal effect

\footnotetext{
${ }^{9}$ The results of a survey conducted in the department of Seine-et-Marne have shown that $23 \%$ of households eligible for FGT are not even aware of the existence of this program. (Anne and Chareyron 2017)
} 
would operate through the consideration of information such that the perceived net costs of participating in the interview are reduced.

The three letters are displayed in appendix figures (Panel A1, A2 and A3). All of them explicitly state the requirement to participate in the guidance interview as well as the penalty for failure to do so; the process of disentitlement will be launched. Note that we do not change their appearance nor their format, which are subject to regulatory specifications. We update only the information that they contain in order to assess the effects of a particular message and wording for the choice of whether or not to participate in the guidance interview.

We randomly assigned subjects to receive one of the three notices (the original letter, the simplified version, and the salient information version), such that the sample sizes are equal and the mean household characteristics of age and gender are equal across the three groups. The causal effect of the information that is conveyed is determined by comparing the participation rate of the three groups.

A series of balancing tests in the form of regression equations were conducted in order to verify the extent to which the randomized selection process produced balanced treatment groups with regards to our observable characteristics. The results presented in Appendix Table A1 show no statistically significant difference in the mean values between the three experimental groups for the age variable. That finds also applies to the derived variable of the transition rate between labour force inactivity and activity. In the case of gender, however, there exists a statistically significant difference in the compositional shares between the control group and the first treatment group. The group that received the simplified letter has a lower share of women.

Figure 1 shows the relative frequency distribution calculated from our sample in elapsed time between the mailing of the letters and the event of the guidance interview. It ranges from 0 to 69 days after the receipt of the mailing, with a mean (median) of 18 (17) days and a standard deviation of 9.1 days. The long durations that are observed for some households are mainly due to the fact that beneficiaries might have had to wait before the interview can be arranged, even if they contacted their case worker within the seven-day interval. 
Figure 1: Distribution of elapsed time between the sending of the letter and participation in the guidance interview

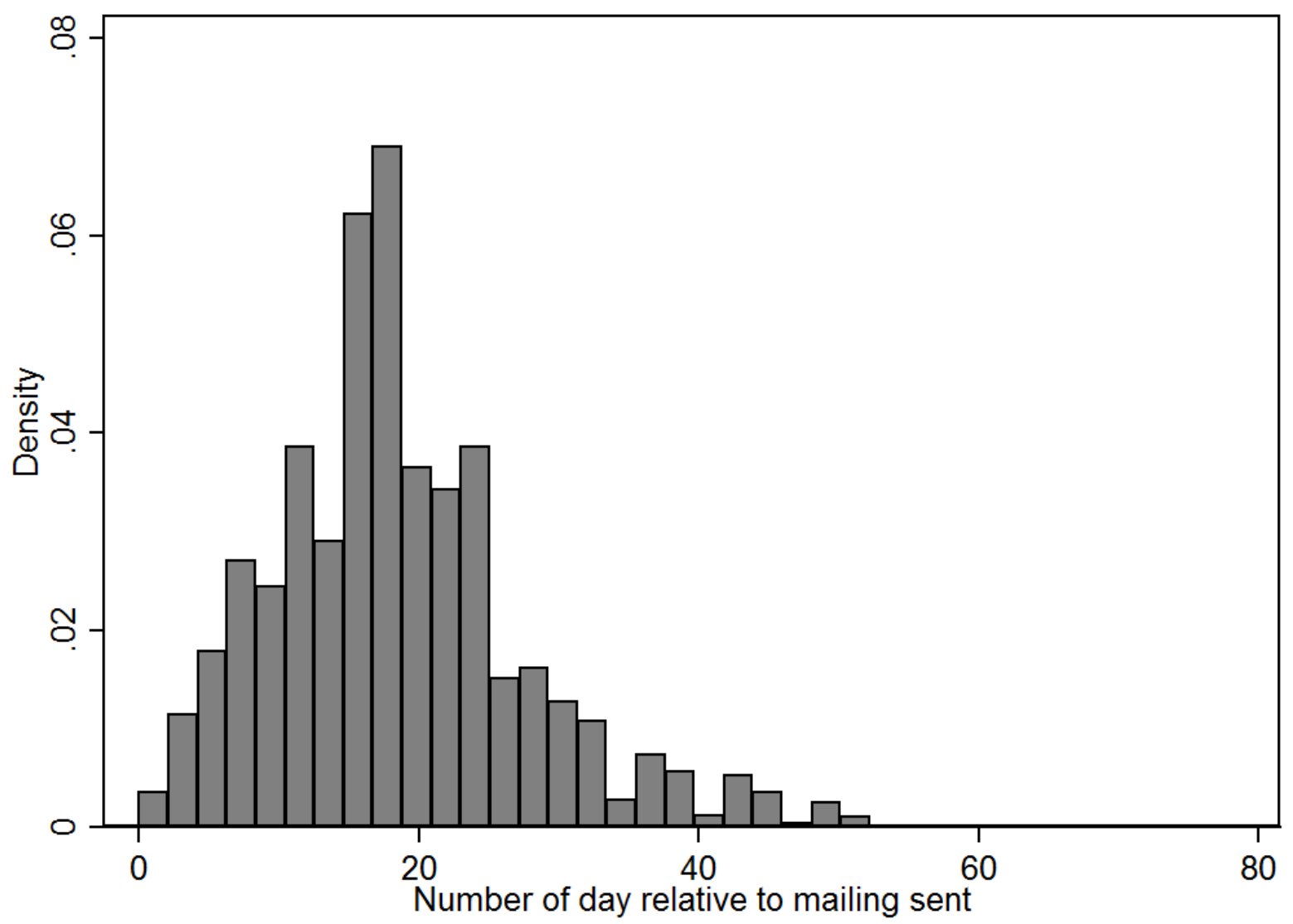

Notes: This figures depicts the relative frequency of new entrants in the income support program who participate to the guidance interview each day following the sending of the mails.

Sources: Data were provided by the General council of Seine-et-Marne.

\section{Results}

\section{a. Response to Experimental Treatments}

The findings presented in Table 1 pertain only to the control group. The figures represent the participation rates for the guidance interview cross-tabulated by age and gender. The estimated standard errors appear in parentheses. Overall only $55 \%$ of the households in the control group participate in the guidance interview, despite the risks that are mentioned in the discussion above. At first glance it appears that this participation rate does not vary much with the age or the gender of the respondent. The null hypotheses of no differences between the groups cannot be rejected. 
Table 1: Participation rate of the control group by age and gender

\begin{tabular}{c|c|c|c}
\hline & All & Males & Females \\
\hline Younger than 28 & 53.8 & 55.3 & 52.8 \\
& $(49.9)$ & $(49.9)$ & $(50.0)$ \\
\multirow{3}{*}{28 or older } & 55.5 & 54.4 & 56.5 \\
& $(49.7)$ & $(49.8)$ & $(49.6)$ \\
\hline All & 55.0 & 54.7 & 55.4 \\
& $(49.7)$ & $(49.8)$ & $(49.7)$ \\
\hline
\end{tabular}

Notes: This table presents the participation rates of the control group cross-tabulated by age and gender.

Table 2 presents the differences in participation rates between the control group and the two distinct treatment groups for the entire sample as well as the breakdowns by age and gender. The null hypothesis for each cell is the absence of any difference in the incidence of this outcome between the two respective groups. Significance levels are based on bilateral non-parametric tests of equality between two proportions. Compared to the control group, the overall participation rate is, as expected, higher for each of the two treatment groups, but these discrepancies are not statistically significant. This absence of significance at the conventional levels could be due to a lack of statistical power of the estimation. Given our relatively low sample size, we have less than a $30 \%$ of chance of rejecting the null hypothesis at the $10 \%$ level for an estimated 2 percentage-point difference in the estimates between any two groups. Based on those findings, we assert that the impacts of the variations in the mailings are not substantial for the entire sample.

We now turn our attention to an analysis based on less-aggregated control and treatment groups that are categorized by age and gender. There does appear to be a strong effect for the salient information letter among men younger than 28 years. Among the sample of younger men, the participation rate for that treatment group is 11.6 percentage points (and $22 \%$ ) higher than the corresponding figure for the control group. The participation rate of these households reaches almost $67 \%$ compared to $55 \%$ for the control group. ${ }^{10}$

None of the other comparisons of the participation rates yield statistically significant differences between the treatment groups and the control groups. We discern no patterns

\footnotetext{
${ }^{10}$ In our global sample, there are 394 subjects whose birth date is unknown. These subjects are excluded from our primary analysis. Restricting our calculations to only this sample, the participation rate for the salient information mailing is almost 10 points higher than the corresponding figure for the control group, and the null hypothesis can be rejected at the $10 \%$ level of significance.
} 
involving either the female samples or the older samples (i.e. over 28 years of age). The simplified mailing does not bring about a statistically significant increase in the participation rate. $^{11}$

Table 2: Participation rate comparisons

\begin{tabular}{|c|c|c|c|c|c|}
\hline \multirow{2}{*}{$\begin{array}{c}\text { Pairwise } \\
\text { comparisons }\end{array}$} & \multirow{2}{*}{$\begin{array}{l}\text { Whole } \\
\text { sample }\end{array}$} & \multicolumn{2}{|c|}{ Males } & \multicolumn{2}{|c|}{ Females } \\
\hline & & $\begin{array}{l}\text { Younger } \\
\text { than } 28\end{array}$ & 28 and older & $\begin{array}{l}\text { Younger } \\
\text { than } 28\end{array}$ & 28 and older \\
\hline Simplified & 0.66 & 3.12 & -1.36 & 0.57 & 0.00 \\
\hline Mailing & $(2.11)$ & $(5.77)$ & $(3.95)$ & $(4.93)$ & $(3.60)$ \\
\hline $\begin{array}{c}\text { Salient } \\
\text { information }\end{array}$ & 1.32 & 11.55 & -1.76 & 0.68 & -2.44 \\
\hline Mailing & (2.19) & (5.67) & $(4.25)$ & $(4.59)$ & $(3.56)$ \\
\hline
\end{tabular}

\section{b. Interpretation of findings}

Our experiment generates empirical patterns according to gender and age group. We discern a strong and positive effect on the participation rate only in the case of the salient information mailing (i.e. the second treatment), and that impact only applies to the sample composed of young men. Note that it is not unusual to obtain results which vary by age and gender in RCTs consisting of informational variation provided to subjects. For instance, Liebman and Luttmer (2015) conducted an RCT that dealt with the Social Security Regime of the USA, which is their primary public retirement pension program. When they varied the information that was provided to older (yet still active) workers regarding key provisions, they uncovered a stronger impact for women than for men.

In order to interpret our result regarding younger men, we investigate the labour market outcomes that might be specific to that particular group. We utilise the French Enquête

\footnotetext{
${ }^{11}$ As we noted above, due to our fairly small sample sizes and to the level of initial participation (about $50 \%$ ) which lead to a fairly high variance, the estimation procedures lack power. The estimation on subpopulations that are conducted here were planned before the beginning of the experiment which limits the increase in type 1 error that induce multiple comparisons. But the results are not significant using the conservative Bonferonni correction for multiple comparisons. Thus significant results should be viewed with some caution.
} 
sur l'Emploi (the Labor Force Survey, which is the equivalent of the CPS in the USA) in search of possible behavioural explanations for the discernable increase that we estimated for that sample. Figure 2 presents variations tabulated by age in the quarterly rate of transition between the states of labour market inactivity and employment, with a separate curve for each gender in order to facilitate comparisons. It shows that for men, the maximum transition rate of $14 \%$ is reached at age 28. By contrast the transition rate for women is lower at almost all ages, and it reaches a peak of $11 \%$ at about 26 years of age. The position of these curves suggests that among younger inactive individuals, men tend to exhibit a higher propensity to gain employment than their female counterparts. It is possible that they are better positioned to search for employment due to factors such as health or family responsibilities, or lack therefor the latter factor.

In support of this interpretation, we appeal to questions contained in that survey that explicitly address the job search intensity of unemployed workers. The Labor Force Survey shows a negative correlation between the age and the number of applications sent out in searching for a job as well as an indicator for training activity following unemployment. ${ }^{12}$ This is confirmed by the study of Gossiaux and Pommier (2013), which shows a decreasing relationship between the incidence of professional training and the age of both unemployed workers as well as inactive workers. The study indicates also that cost and familial responsibilities are the main reasons provided by those who drop out of training programs. Younger men might be more interested and influenced by information pertaining to the active aids facilitating labour market integration than is the case for other inactive groups. The new information that is provided in the salient information letter might lead some young men to reevaluate upward the value of the option requiring participation in the guidance interview. The updating of the perceived benefits might now offset the unexpected cost of the multistep process about which many appear to be apprehensive.

Because we discern no empirical results regarding the treatment of the simplified letter, we suggest that a failure to participate in the guidance interview does not appear to result from a problem of misunderstanding the essence of that letter. As explained above, the standard, original letter is already pretty brief, and it contains little more than a basic message - namely that the recipient only needs to contact their case-worker - which is tied very directly to our outcome variable. Recipients with serious reading or comprehension

\footnotetext{
${ }^{12}$ These tendencies are in line with those find on the employed by Demailly (2016).
} 
difficulties may already have been flagged at the initial stage of their claim to the income support program and may be rare in our sample of beneficiaries. For those reasons, recipients with those characteristics are probably not reflected in our results.

Figure 2: Quarterly rates of transition between inactivity and employment in France 2012

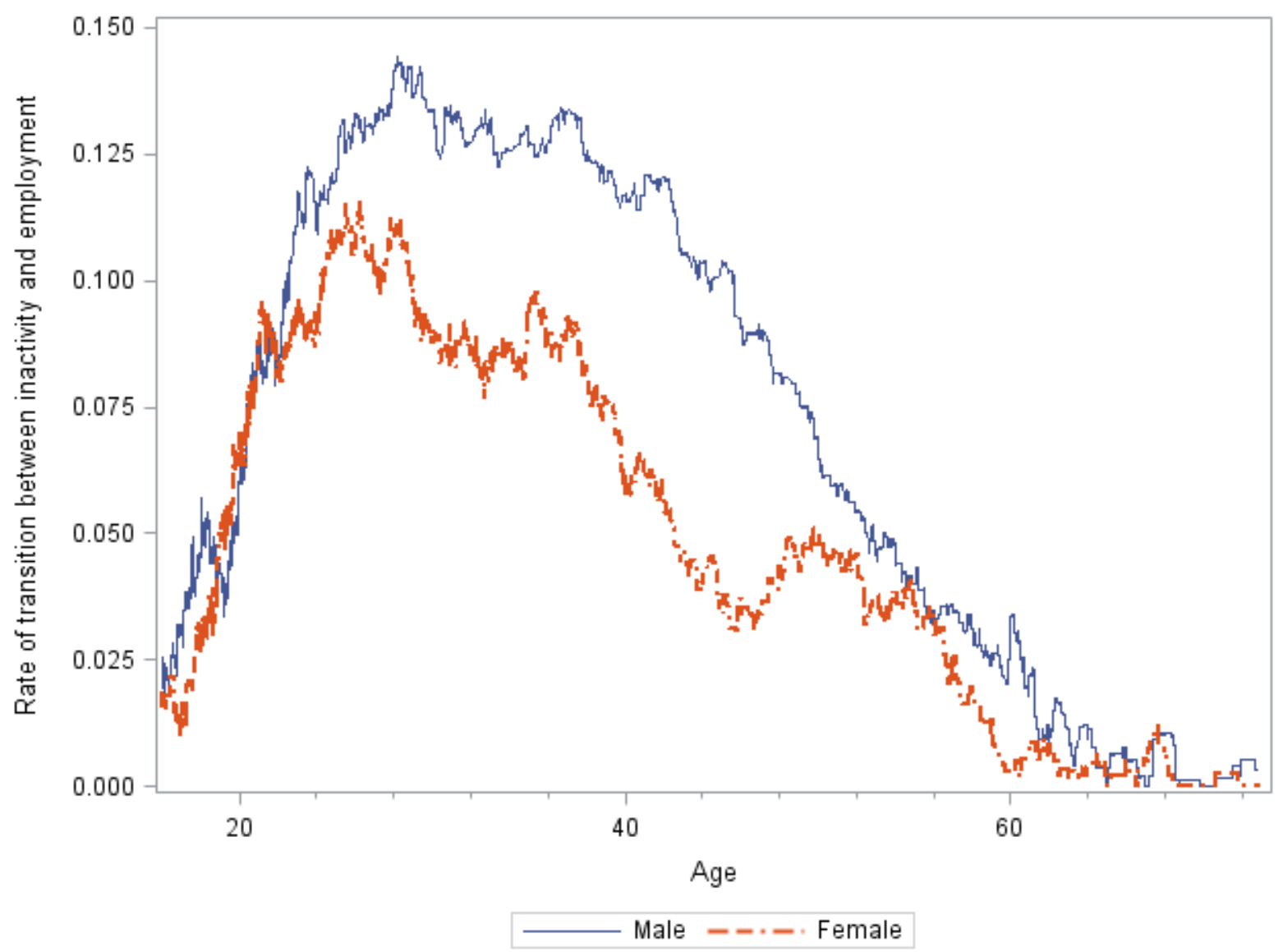

Notes: Rates of transition are calculated for a moving segment of 500 households sort in ascendant order of age. Lecture: $14 \%$ of 28 years old inactive men in the third quarter of 2012 are in employment in the last quarter of 2012. Sources: Labor Force Survey 2012.

\section{Conclusion}

This study consists of an experimental field experiment that was conducted in order to investigate the puzzle of an unduly high non-take-up rate for social assistance benefits in France. We focused our attention on one dimension of the topic of take-up, namely the exclusion of recipient households from the program, i.e. disentitlement to receiving benefits, subsequent to the initiation of benefits stemming from a failure to comply with a critical regulation. Taking a perspective drawn from behavioural economics, we tested two hypotheses related to the behavioural bias of inattention, whereby individuals have a tendency 
to overlook important decisions. In the spirit of behavioural insights often associated with Sunstein (2014) and Thaler (2015), our experiment consists of generating two informational "nudges" taking the form of two minor and subtle variations in an official letter that were sent to randomly selected groups. These letters notified beneficiaries of an obligation to present themselves to an interview with a case worker under threat of a cutoff in benefit receipt. The event of compliance is the outcome variable.

Our findings indicate that the mailing informing recipients about the advantages (in the form of active labour market policy benefits) related to the passive income support benefits increases substantially the participation of young men in the interviewing process. This result appears to be restricted to this particular sample, however, because the estimated effect is not significant for either the entire sample or for other subsamples. We suggest that this contrasted result may be the consequence of the greater observed propensity of inactive young men to join or re-enter the labour force compared to the samples of older men, older women, and younger women. The other letter, which consisted of a simplified version, does not appear to have statistically significant effects on the variable of participation in the guidance interview.

Our findings suggest that the take-up of social assistance benefits, through the channel of avoiding disentitlement to benefits and thus ensuring continuous receipt, can be increased by the simple and costless action of providing just a bit more information in regards to extant but often unknown related benefits. Depending on the nature of these highlighted benefits, the action may have a greater impact on certain segments of the inactive population. Our results suggest that governments have little to lose by providing further information about the set of benefits - typically taking the form of activation measures - accompanying the social assistance regime.

We note that in contrast to some of the existing research on the issue of non-take-up, which is focused solely on the behavior of beneficiaries, a policy repercussion of our analysis places some onus on the design and administration of social assistance programs. The quality of the information transmitted to recipients and the response times of the administration likely play some role in the non-take-up and non-continuation phenomena. Ideally information should be suited to the particular needs of the recipients and is therefore likely to improve their access to these benefits. Indeed the objective of the guidance interview is to learn something about these needs. In our experimental analysis, a small improvement or 
enrichment in the information that is initially provided to beneficiaries through formal letters can not only raise take-up, but facilitate the implementation of a personalized plan with an eye towards re-integration into the labour market.

First on the agenda for further research is to obtain larger estimating samples such that the power of our statistical analysis is reinforced. It would also be highly desirable to conduct a survey involving beneficiaries' attributes that could be linked to the administrative data. As far as the external validity of our analysis is concerned, it applies to social assistance programs that offer related benefits and subject their beneficiaries to a meeting requirement. We note that we cannot rule out other explanations for the high rate of non-compliance for the required interview. An important but unknown factor is the degree to which the threat of suspension of benefit payment in case of non-participation is perceived as credible by beneficiaries. Another relevant explanatory variable is the lags that occur between the time when the beneficiary does contact the case-worker (which is not reported) and the time that the guidance interview does take place. Subsequent research should attempt to address these issues. 


\section{References:}

Anne, D., and S. Chareyron. 2017. "Une Analyse Spatiale Du Non-Recours Aux Dispositifs Sociaux." Revue d'Economie Politique, à paraître.

Bargain, O., H. Immervoll, and H. Viitamäki. 2012. "No Claim, No Pain. Measuring the NonTake-up of Social Assistance Using Register Data." Journal of Economic Inequality, 10: 375-395,.

Bertrand, Marianne, Sendhil Mullainathan, and Eldar Shafir. 2006. "Behavioral Economics and Marketing in Aid of Decision Making Among the Poor." Journal of Public Policy \& Marketing 25 (1): 8-23. doi:10.1509/jppm.25.1.8.

Bettinger, E. P., B. T. Long, P. Oreopoulos, and L. Sanbonmatsu. 2012. "The Role of Application Assistance and Information in College Decisions: Results from the H\&amp;R Block Fafsa Experiment." Quarterly Journal of Economics 127 (3): 120542. doi:10.1093/qje/qjs017.

Bhargava, Saurabh, and George Loewenstein. 2015. "Behavioral Economics and Public Policy 102: Beyond Nudging." American Economic Review 105 (5): 396-401. doi:10.1257/aer.p20151049.

Bhargava, Saurabh, and Dayanand Manoli. 2015. "Psychological Frictions and the Incomplete Take-Up of Social Benefits: Evidence from an IRS Field Experiment." American Economic Review 105 (11): 3489-3529. doi:10.1257/aer.20121493.

Chareyron, Sylvain. 2014. "Le Non-Recours Au RSA «Socle Seul»: L'hypothèse Du Patrimoine.” TEPP Research Report 2014-03. TEPP.

Chareyron, Sylvain, and Patrick Domingues. 2016. "Take-Up of Social Assistance Benefits: The Case of the French Homeless." Review of Income and Wealth, November. doi:10.1111/roiw.12274.

Chetty, Raj, and Emmanuel Saez. 2013. "Teaching the Tax Code: Earnings Responses to an Experiment with EITC Recipients." American Economic Journal: Applied Economics 5 (1): 1-31. doi:10.1257/app.5.1.1.

Currie, Janet. 2006. "The Take-up of Social Benefits." In Public Policy and the Income Distribution, New York: Russell Sage Foundation, 80-148. Alan J. Auerbach, David Card, and John M. Quigley.

Daponte, Beth Osborne, Seth Sanders, and Lowell Taylor. 1999. "Why Do Low-Income Households Not Use Food Stamps? Evidence from an Experiment." Journal of Human Resources 34 (3): 612. doi:10.2307/146382.

Demailly, Dominique. 2016. "Formation Professionnelle: Quels Facteurs Limitent L'accès Des Salariés Seniors ?" DARES Analyses, no. 31.

Domingo, Pauline, and Muriel Pucci. 2011. "Le Non-Recours Au Revenu de Solidarité Active." Annexe 1 du rapport du Comité national d'évaluation du RSA.

Duflo, Esther, and Emmanuel Saez. 2003. "The Role of Information and Social Interactions in Retirement Plan Decisions: Evidence from a Randomized Experiment." Quarterly Journal of Economics 118 (3): 815-42.

French, Robert, and Philip Oreopoulos. 2016. "Applying Behavioral Economics to Public Policy in Canada." w22671. Cambridge, MA: National Bureau of Economic Research. http://www.nber.org/papers/w22671.pdf.

Gossiaux, Sébastien, and Patrick Pommier. 2013. "La Formation Des Adultes Un Accès plus Fréquent Pour Les Jeunes, Les Salariés Des Grandes Entreprises et Les plus Diplômés." INSEE Première, no. 1468.

Hallsworth, Michael, John List, Robert Metcalfe, and Ivo Vlaev. 2014. "The Behavioralist As Tax Collector: Using Natural Field Experiments to Enhance Tax Compliance." 
w20007. Cambridge, MA: National Bureau of Economic Research. http://www.nber.org/papers/w20007.pdf.

Hastings, Justine S., and Jeffrey M. Weinstein. 2008. "Information, School Choice, and Academic Achievement: Evidence from Two Experiments *" Quarterly Journal of Economics 123 (4): 1373-1414. doi:10.1162/qjec.2008.123.4.1373.

Jones, Damon. 2010. "Information, Preferences, and Public Benefit Participation: Experimental Evidence from the Advance EITC and 401(k) Savings." American Economic Journal: Applied Economics 2 (2): 147-63. doi:10.1257/app.2.2.147.

Liebman, Jeffrey B., and Erzo F. P. Luttmer. 2015. "Would People Behave Differently If They Better Understood Social Security? Evidence from a Field Experiment $\dagger . "$ American Economic Journal: Economic Policy 7 (1): 275-99. doi:10.1257/pol.20120081.

Madrian, B. C., and D. F. Shea. 2001. "The Power of Suggestion: Inertia in 401(k) Participation and Savings Behavior." Quarterly Journal of Economics 116 (4): 114987. doi:10.1162/003355301753265543.

Milkman, K. L., J. Beshears, J. J. Choi, D. Laibson, and B. C. Madrian. 2011. "Using Implementation Intentions Prompts to Enhance Influenza Vaccination Rates." Proceedings of the National Academy of Sciences 108 (26): 10415-20. doi:10.1073/pnas.1103170108.

Moffitt, R. 1983. “An Economic Model of Welfare Stigma.” American Economic Review, 73: 1023-35,.

Mullainathan, Sendhil, and Eldar Shafir. 2013. Scarcity: Why Having Too Little Means so Much. London: Allen Lane.

O’Donoghue, Ted, and Matthew Rabin. 1999. "Doing It Now or Later." American Economic Review 89 (1): 103-24. doi:10.1257/aer.89.1.103.

Riphahn, Regina T. 2001. "Rational Poverty or Poor Rationality? The Take-Up Study of Social Assistance Benefits." Review of Income and Wealth 47 (3): 379-98.

Saez, Emmanuel. 2009. "Details Matter: The Impact of Presentation and Information on the Take-up of Financial Incentives for Retirement Saving." American Economic Journal: Economic Policy 1 (1): 204-28.

Sunstein, Cass R. 2014. "Nudging: A Very Short Guide." Journal of Consumer Policy 37 (4): 583-88. doi:10.1007/s10603-014-9273-1.

Tempelman, C., and A. Houkes-Hommes. 2015. "What Stops Dutch Households from Taking Up Much Needed Benefits?" Review of Income and Wealth,.

Terracol, Antoine. 2002. "Coûts de Perception et Taux de Non-Recours Aux Prestations Sous Conditions de Ressources.” Les Cahiers de La MSE, Série Blanche n 2002.07.

Thaler, Richard H. 2015. Misbehaving: The Making of Behavioral Economics. New York: W. W. Norton \& Company, Inc. 


\section{Appendix}

\section{Balancing check}

Table A1: Balancing check of experimental treatments

\begin{tabular}{lccc}
\hline & \multicolumn{3}{c}{ Dependent variable } \\
\cline { 2 - 4 } VARIABLES & Male & $\begin{array}{c}\text { Transition between } \\
\text { inactivity and } \\
\text { employment }\end{array}$ \\
\hline Simple mailing & $-0.0618^{* *}$ & -0.209 & -0.00124 \\
Salient & $(0.0195)$ & $(0.597)$ & $(0.00177)$ \\
mailing & & & \\
& -0.0333 & -0.838 & 0.00102 \\
Constant & $(0.0194)$ & $(0.558)$ & $(0.00179)$ \\
& $0.453^{* *}$ & $35.35^{* *}$ & $0.0896^{* *}$ \\
Observations & $(0.0120)$ & $(0.431)$ & $(0.00132)$ \\
Fisher test & & & 3,638 \\
R-squared & 4,032 & 3,638 & 1.18 \\
\hline
\end{tabular}

Notes: This table reports the outcome of a series of regressions meant to test whether the experimental randomization produced balanced treatment groups across our observable characteristics. Robust standard errors clustered at each city in parentheses, ** $p<0.01, * p<0.05$. 


\title{
Experimental interventions
}

Panel A1: Control mailing

\section{ASSISTANT GENERAL DIRECTION OF SOLIDARTTY \\ Directorate for Inclusion, Housing and Social Cohesion \\ Department for Occupational Integration}

\author{
«Gendero wFamily names eFirst names \\ 4Address" \\ «postal coden *Cityw \\ Melun, $\alpha$ date $w$
}

«Name and surname», (RSA).

You are currently in receipt of the Revenu de Solidarite Active

You must be followed by one designated case-worker in order to discuss and draft your labour market integration plan.

In accordance with regulations, from now on we refer you to the Employment Assistance Association named below. You absolutely must contact this association within 7 days.

\author{
«Name of the assocation" \\ «Address of the associations \\ epostal code of the associations *City of the associations \\ *Phone number of the associations
}

An appointment will be proposed to you in order to establish the assistance plan which is best suited for you and to comply with the contractual obligations to which you are subjected.

In the event that you are unable to fulfill this obligation, or if you are no longer in receipt of the RSA, please indicate as much to this association.

We remind you that the Head of the General Council would be obligated to commence the process of suspending payment of your RSA benefits were you not to fulfill that obligation.

Yours sincerely,

On behalf of the Head of the General Council,

COUNTY OE SEINE-ET-MARENE

D.G.A.S D.1.H.C.S. - Department fix accupation integration

HOTE. OF THE COUNTY

CS 90377

molo-MELN Cal

용 :01.64.14.60.69

a : 01.64 .14 .60 .66 
Panel A2: Simplified mailing

\title{
ASSISTANT GENERAL DIRECTION OF SOLIDARTTY \\ Directorate for Inclusion, Housing and Social Cohesion \\ Department for Occupational Integration
}

\author{
«Gendero *Family namen *First name* \\ «Address \\ *ZIP coden *City*
}

Melun, * date w

«Name and surnamen,

You are in receipt of Revenu de Solidarite Active (RSA) benefits.

In order to continue to receive them, you absolutely must contact this association within 7 days:

\author{
Name of the assocation \\ $\alpha$ Address of the association $x$ \\ * ZIP code of the associations $*$ City of the associations \\ whone number of the association
}

An appointment will be proposed to you in order to present you with the assistance to which you are entitled and to have you sign the commitment contract.

In the event that you are unable to do so, or if you are no longer in receipt of RSA benefits, please indicate as much to the association.

1 remind you that the Head of the General Council would be obligated to commence the process of suspending payments of your RSA benefits were you not to fulfill this obligation.

Yours sincerely,

On behalf of the Head of the General Council,

COUNTY OE SFINE-ET-MARONE

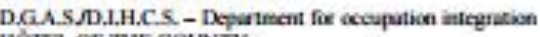

HOTE. OF MAE COUNTY

CS 90377

77010-MEUN Cede

e: :01.64.1460.69

a : $01.64 .14,60.66$ 
Panel A3: Salient information mailing

\title{
ASSISTANT GENERAL DIRECTION OF SOLIDARITY \\ Directorate for Inclusion, Housing and Social Cohesion \\ Department for Occupational Integration
}

\author{
«Gender $*$ Family name $*$ First name \\ «Addressw \\ «postal codew *Cityw \\ Melun, $\alpha$ date $w$
}

«Name and surnamen, benefits.

You are in receipt of Revenu de Solidarité Active (RSA)

You are entitled to a personalized benefits which will assist you in integrating into the labour market. You will be assigned to a particular case worker in order to design a plan that is designed for you.

I also remind you that the receipt of the RSA gives you the right to access related benefits, such as free access to public transportation.

In order to continue to receive the payments and to benefit from the assistance measures, you must contact this association within 7 days:

\author{
«Name of the assocationw \\ «Address of the associations \\ wpostal code of the associations *City of the associations \\ «Phone number of the associations
}

An appointment will be proposed to you in order to present you with the assistance measures to which you are entitled and to have you sign the commitment contract.

In the event that you are unable to do so, or if you are no longer in receipt of the RSA benefits, please indicate as much to the association.

I remind you that the Head of the General Council would be obligated to commence the process of suspending payment of your RSA benefits if you were not to fulfill these obligations.

Yours sincerely,

On behalf of the Head of the General Council,

COUNTY OE SEINE-ET-MARNE

D.G.A.S.J.I.H.C.S. - Depertment fie accupation integracion

HOTEL. OF THE COUNTY

CS 90377

77010-MELUN Cede:

을 :01.64.14.60.69

a : 01.64 .14 .60 .66 
16-8. Endogenous wage rigidities, human capital accumulation and growth Ahmed Tritah

16-7. Harder, better, faster...yet stronger? Working conditions and self-declaration of chronic diseases

Eric Defebvre

16-6. The influence of mental health on job retention

Thomas Barnay, Eric Defebvre

16-5. The effects of breast cancer on individual labour market outcomes: an evaluation from an administrative panel

Thomas Barnay, Mohamed Ali Ben Halima, Emmanuel Duguet, Christine Le Clainche, Camille Regaert

16-4. Expectations, Loss Aversion, and Retirement Decisions in the Context of the 2009 Crisis in Europe

Nicolas Sirven, Thomas Barnay

16-3. How do product and labor market regulations affect aggregate employment, inequalities and job polarization? A general equilibrium approach

Julien Albertini, Jean-Olivier Hairault, François Langot, Thepthida Sopraseuth

16-2. Acces to employment with age and gender: results of a controlled experiment Laetitia Challe, Florent Fremigacci, François Langot, Yannick L'Horty, Loïc Du Parquet, Pascale Petit

16-1. An evaluation of the 1987 French Disabled Workers Act: Better paying than hiring

Thomas Barnay, Emmanuel Duguet, Christine Le Clainche, Yann Videau 
15-10. Optimal Income Taxation with Unemployment and Wage Responses: A Sufficient Statistics Approach

Kory Kroft, Kavan Kucko, Etienne Lehmann, Johannes Schmieder

15-9. Search frictions and (in) efficient vocational training over the life-cycle Arnaud Chéron, Anthony Terriau

15-8. Absenteeism and productivity: the experience rating applied to employer contributions to health insurance

Sébastien Ménard, Coralia Quintero Rojas

15-7. Take up of social assistance benefits: the case of homeless

Sylvain Chareyron

15-6. Spatial mismatch through local public employment agencies. Answers from a French quasi-experiment

Mathieu Bunel, Elisabeth Tovar

15-5. Transmission of vocational skills at the end of career: horizon effect and technological or organisational change

Nathalie Greenan, Pierre-Jean Messe

15-4. Protecting biodiversity by developing bio-jobs: A multi-branch analysis with an application on French data

Jean De Beir, Céline Emond, Yannick L'Horty, Laetitia Tuffery

15-3. Profit-Sharing and Wages: An Empirical Analysis Using French Data Between 2000 and 2007

Noélie Delahaie, Richard Duhautois

15_2. A meta-regression analysis on intergenerational transmission of education: publication bias and genuine empirical effect

Nicolas Fleury, Fabrice Gilles

15_1. Why are there so many long-term unemployed in Paris?

Yannick L'Horty, Florent Sari 
TEPP Working Papers 2014

14-14. Hiring discrimination based on national origin and the competition between employed and unemployed job seekers

Guillaume Pierné

14-13. Discrimination in Hiring: The curse of motorcycle women

Loïc Du Parquet, Emmanuel Duguet, Yannick L'Horty, Pascale Petit

14-12. Residential discrimination and the ethnic origin: An experimental assessment in the Paris suburbs

Emmanuel Duguet, Yannick L'Horty, Pascale Petit

14-11. Discrimination based on place of residence and access to employment

Mathieu Bunel, Yannick L'Horty, Pascale Petit

14-10. Rural Electrification and Household Labor Supply: Evidence from Nigeria

Claire Salmon, Jeremy Tanguy

14-9. Effects of immigration in frictional labor markets: theory and empirical evidence from $E U$ countries

Eva Moreno-Galbis, Ahmed Tritah

14-8. Health, Work and Working Conditions: A Review of the European Economic Literature

Thomas Barnay

14-7. Labour mobility and the informal sector in Algeria: a cross-sectional comparison (2007-2012)

Philippe Adair, Youghourta Bellache

14-6. Does care to dependent elderly people living at home increase their mental health? Thomas Barnay, Sandrine Juin

14_5. The Effect of Non-Work Related Health Events on Career Outcomes: An Evaluation in the French Labor Market

Emmanuel Duguet, Christine le Clainche

14_4. Retirement intentions in the presence of technological change: Theory and evidence from France

Pierre-Jean Messe, Eva Moreno - Galbis, Francois-Charles Wolff

14_3. Why is Old Workers' Labor Market more Volatile? Unemployment Fluctuations over the Life-Cycle

Jean-Olivier Hairault, François Langot, Thepthida Sopraseuth

14_2. Participation, Recruitment Selection, and the Minimum Wage

Frédéric Gavrel 
14_1. Disparities in taking sick leave between sectors of activity in France: a longitudinal analysis of administrative data

Thomas Barnay, Sandrine Juin, Renaud Legal

TEPP Working Papers 2013

13_9. An evaluation of the impact of industrial restructuring on individual human capital accumulation in France (1956-1993)

Nicolas Fleury, Fabrice Gilles

13_8. On the value of partial commitment for cooperative investment in buyer-supplier relationship

José de Sousa, Xavier Fairise

13-7. Search frictions, real wage rigidities and the optimal design of unemployment insurance

Julien Albertini, Xavier Fairise

13-6. Tax me if you can! Optimal non linear income tax between competing governments Etienne Lehmann, Laurent Simula, Alain Trannoy

13-5. Beyond the labour income tax wedge: The unemployment-reducing effect of tax progressivity

Etienne Lehmann, Claudio Lucifora, Simone Moriconi, Bruno Van Der Linden

13-4. Discrimination based on place of residence and access to employment

Mathieu Bunel, Emilia Ene Jones, Yannick L'Horty, Pascale Petit

12-3. The determinants of job access channels: evidence from the youth labor market in Franc

Jihan Ghrairi

13-2. Capital mobility, search unemployment and labor market policies: The case of minimum wages

Frédéric Gavrel

13-1. Effort and monetary incentives in Nonprofit et For-Profit Organizations Joseph Lanfranchi, Mathieu Narcy 
The CNRS Institute for Labor Studies and Public Policies (the TEPP Institute, FR n³435 CNRS) gathers together research centres specializing in economics and sociology:

- L'Equipe de Recherche sur l'Utilisation des Données Individuelles en lien avec la Théorie Economique (Research Team on Use of Individuals Data in connection with economic theory), ERUDITE, University of Paris-Est Créteil and University of ParisEst Marne-la-Vallée

- Le Centre d'Etudes des Politiques Economiques de l'université d'Evry (Research Centre focused on the analysis of economic policy and its foundations and implications), EPEE, University of Evry Val d'Essonne

- Le Centre Pierre Naville (Research on Work and Urban Policies), CPN, University of Evry Val d'Essonne

- Le Groupe d'Analyse des Itinéraires et des Niveaux Salariaux (Group on Analysis of Wage Levels and Trajectories), GAINS, University of the Maine

- Le Centre de Recherches en Economie et en Management, (Research centre in Economics and Management), CREM, University of Rennes 1 et University of Caen Basse-Normandie

- Le Groupe de Recherche ANgevin en Économie et Management (Angevin Research Group in Economics and Management), GRANEM, University of Angers ;

- Le Centre de Recherche en Economie et Droit (Research centre in Economics and Law) CRED, University of Paris II Panthéon-Assas ;

- Le Laboratoire d'Economie et de Management Nantes-Atlantique (Laboratory of Economics and Management of Nantes-Atlantique) LEMNA, University of Nantes ;

- Le Laboratoire interdisciplinaire d'étude du politique Hannah Arendt - Paris Est, LIPHA-PE

The TEPP Institute brings together 190 researchers and research professors and $140 \mathrm{PhD}$ students who study changes in work and employment in relation to the choices made by firms and analyse public policies using new evaluation methods. 